\title{
Diagnóstico del proceso de producción artesanal de la mujer ñañho en Querétaro, México
}

\author{
Diagnosis of the artisan production process of the ñañho woman in Querétaro, México
}

\author{
Rosalía Alonso Chombo ${ }^{1}$ \\ Jorge Adán Romero Zepeda ${ }^{2}$ \\ Xenia Paola Cárdenas Álvarez ${ }^{3}$
}

\section{Resumen}

La presente investigación ha documentado el proceso de producción artesanal elaborado por la mujer ñañho, para proponer una estrategia organizativa culturalmente satisfactoria y más rentable. Se parte del supuesto de que la mujer ñañho artesana podría conseguir mejores condiciones laborales si tiene consciencia clara de todos los elementos que intervienen en su proceso productivo; a su vez, de que sería beneficiada de estructurar su proceso productivo como una empresa formal, ya que con ello podría beneficiarse de los programas gubernamentales dirigidos a la producción artesanal. Como metodología, se llevaron a cabo 1 entrevista a informante clave, 1 entrevista grupal y una encuesta a 24 mujeres indígenas. Al respecto, en trabajo de campo se observa que la división del trabajo se da principalmente por género y edades dentro del núcleo familiar, existen grandes diferencias en el proceso de producción y laboral desde el sector informal que es la regla. A partir de lo anterior, se concluye que la conformación de un proceso formal productivo no puede establecerse de manera inmediata, sino que requerirá previamente de una intervención de integración comunitaria.

Palabras clave: artesanía; género; indígena; proceso de producción.

\section{Abstract}

The present investigation has documented the process of handicraft production elaborated by ñañho women to propose a culturally satisfactory and more profitable organizational strategy. It is assumed that ñañho artisan women could achieve better working conditions if they have a clear awareness of all the elements that intervene in their productive process; besides, that it would benefit from structuring its productive process as a formal enterprise, since it could be benefited from government programs

\footnotetext{
1 Doctora en Administración. Profesora de la Universidad Autónoma de Querétaro Campus Amealco, Facultad de Contaduría y Administración. Correo: rosalia.alonso@uaq.mx; No. ORCID: https://orcid.org/oooo-ooo1-5751-8108

2 Doctor en Ciencias Sociales con orientación en Desarrollo Sustentable. Profesor-Investigador de la Universidad Autónoma de Querétaro Campus Amealco, Facultad de Contaduría y Administración. Correo: romerozepedajorgeadan@gmail.com; No. ORCID: https://orcid.org/oooo-ooo1-5751-8108

3 Maestra en Derecho. Profesora de la Universidad Autónoma de Querétaro Campus Amealco, Facultad de Derecho. Correo: derechoamealco@gmail.com; No. ORCID: https://orcid.org/oooo-ooo1-5751-8108
}

Recibido: 05/02/2018 Aprobado:30/04/2018 
aimed at artisanal production. As methodology, 1 interview with a key informant, 1 group interview and a survey of 24 indigenous women were carried out. In this regard, in fieldwork it is observed that the division of labor occurs mainly by gender and ages within the family nucleus, there are great differences in the production and labor process from the informal sector that is the rule. Based on the above, it is concluded that the formation of a formal productive process cannot be established immediately, but will require prior community integration intervention.

Keywords: crafts, gender, indigenous, production process.

\section{Introducción}

Los productos artesanales son el reflejo de actividades desarrolladas por una parte importante de la población mexicana. En ellos se descubren aspectos relativos a la cultura, a la vida en sociedad, monetarios, prácticos y de intercambio comercial que además cuentan con la aceptación de los visitantes nacionales y extranjeros (Correa, 2016).

Novelo (2002), en su artículo Ser indio, artista y artesano en México, comenta que el trabajo artesanal es una especie de carta de presentación de las comunidades que le dan origen. Estos pueblos cuentan su historia y comparten su esencia con el resto del mundo a través de sus artículos.

La mujer ñañho por medio de su creación artística, la muñeca, transmite su condición, da fe de la gran riqueza cultural que posee, aun cuando ella misma no alcanza a comprender el gran tesoro que sale de sus manos y que comparte con el mundo.

A través de la fabricación y comercialización de la muñeca artesanal la mujer ñañho refleja el papel crucial que ocupa en la economía familiar, pues en muchas ocasiones, ella es el único sostén de la familia, bien sea porque el esposo, quien generalmente es campesino y no goza de una fuente de ingresos segura, o porque él en busca de una mejor vida para su parentela, se vio obligado a emigrar a los Estados Unidos y las remesas no llegan a manos de la artesana en las cantidades y periodicidad necesaria.

Desafortunadamente el sector artesanal carece del impulso necesario para ser considerado como un sector con tendencias claras de crecimiento o marcadas características de eficiencia, pues su ámbito es muy limitado, sólo dependen del gusto y preferencia de los turistas, ya sea locales o internacionales, y consiguientemente, no cuentan con la visión necesaria para poner en práctica maniobras que los hagan más competitivos, sino que en la mayoría de los casos están limitados a la ayuda oficial a través de las políticas sociales, que tienen la vigencia de los gobiernos ya sea municipales, estatales o federal (Correa, 2016). 


\section{Revisión de literatura}

La ocupación del artesano proviene de un sistema de trabajo que va transmitiéndose de generación en generación, sus procesos productivos son emanados de sus usos y costumbres, el capital intelectual que poseen va acumulándose y extendiéndose sólo entre los miembros de su comunidad Novelo (2002).

La mujer ñañho, aprendió de su madre el arte de elaborar muñecas desde su infancia, sabía cómo confeccionarlas, de ella recibió todo el conocimiento necesario para entender el proceso a través del cual se conseguiría el material que sería utilizado para darle vida a su artesanía, cómo combinar texturas, colores, tamaño, material para el relleno, apariencia de los ojos, boca, arreglo del pelo, los moños vistosos, el elegante vestido inspirado tal vez en su propia indumentaria. Su madre, a su vez, recibió toda esa herencia cultural de su progenitora, y actualmente, ella enseñará a sus hijas y nietas, de tal forma que esta tradición no se perderá y será testimonio de la esencia de esta comunidad de artesanas.

La producción de artículos artesanales de los pueblos indígenas está llena de significados culturales, históricos y económicos, en el cuadro 1 se muestra un panorama de la forma en la que se aprecian estos contenidos:

Cuadro 1: Significado cultural, histórico y económico de las artesanías

\begin{tabular}{|l|l|}
\hline \multicolumn{1}{|c|}{ Significado cultural e histórico: } & \multicolumn{1}{c|}{ Significado económico: } \\
\hline El trabajo artesanal es un medio de lucha y memoria. & El trabajo artesanal es una estrategia económica. \\
\hline $\begin{array}{l}\text { El trabajo artesanal representa para sus autores valo- } \\
\text { res que los identifican y donde yace su reminiscencia. }\end{array}$ & $\begin{array}{l}\text { El trabajo artesanal tiene la posibilidad de ser acep- } \\
\text { tado comercialmente en todos los medios econó- } \\
\text { micos. }\end{array}$ \\
\hline $\begin{array}{l}\text { El trabajo artesanal que no se vende, representa para } \\
\text { quien lo produce un satisfactor personal con valores } \\
\text { espirituales. }\end{array}$ & $\begin{array}{l}\text { A lo largo del tiempo las artesanías han recogido del } \\
\text { medio ambiente que las rodea materiales que han } \\
\text { modificado su calidad y cantidad }\end{array}$ \\
\hline $\begin{array}{l}\text { El trabajo artesanal es un medio para transmitir la } \\
\text { cultura de los pueblos indígenas. }\end{array}$ & $\begin{array}{l}\text { El trabajo artesanal es fuente de ingresos, por lo } \\
\text { tanto, aunque de manera informal, es un empleo. }\end{array}$ \\
\hline $\begin{array}{l}\text { El trabajo artesanal es un valor donde se conserva } \\
\text { la tradición y el indígena puede expresarse artística- } \\
\text { mente. }\end{array}$ & $\begin{array}{l}\text { El ingreso que proviene de la actividad artesanal, } \\
\text { si bien, no es considerado formalmente como un } \\
\text { empleo, si cubre todas las necesidades que habi- } \\
\text { tualmente se satisfacen con un salario. }\end{array}$ \\
\hline $\begin{array}{l}\text { El trabajo artesanal se ha enriquecido a través del } \\
\text { tiempo, a fuerza de registrar el peregrinar del grupo } \\
\text { social en su búsqueda de nuevos rumbos. }\end{array}$ & $\begin{array}{l}\text { El indígena productor de artesanías en muchos } \\
\text { casos tiene otras actividades económicas a fin de } \\
\text { satisfacer sus necesidades más apremiantes. }\end{array}$ \\
\hline
\end{tabular}




\begin{tabular}{|l|l|}
\hline \multicolumn{1}{|c|}{ Significado cultural e histórico: } & \multicolumn{1}{c|}{ Significado económico: } \\
\hline $\begin{array}{l}\text { La artesanía no es vista solo como una mercancía, } \\
\text { pues está colmada de valores culturales, históricos y } \\
\text { psicosociales. }\end{array}$ & $\begin{array}{l}\text { El artesano que proviene de un grupo social margi- } \\
\text { nado, como es el indígena no tiene a su alcance los } \\
\text { medios para colocar sus artículos a precios justos y } \\
\text { competitivos. }\end{array}$ \\
\hline $\begin{array}{l}\text { Las artesanías son un bien simbólico, adheridas a las } \\
\text { tradiciones de sus comunidades. }\end{array}$ & $\begin{array}{l}\text { El artesano indígena en la mayoría de los casos } \\
\text { comercializa su producción de manera individual } \\
\text { yesto lo coloca al margen de beneficios guberna- } \\
\text { mentales a los que podría acceder estando organi- } \\
\text { zado en comunidad. }\end{array}$ \\
\hline $\begin{array}{l}\text { Las artesanías dejan ver los cambios en la cotidiani- } \\
\text { dad de los pueblos que las producen y reflejan su } \\
\text { interacción con su entorno social y ambiental. }\end{array}$ & $\begin{array}{l}\text { Cuando el artesano acude a los grandes centros } \\
\text { urbanos pretendiendo comercializar sus productos } \\
\text { es discriminado y sujeto de abusos de toda índole. }\end{array}$ \\
\hline
\end{tabular}

Fuente: Elaboración propia con base en Del Carpio (2012)

La intensión de los artesanos al producir los artículos que comercializan, parte de la necesidad, en primera instancia de preservar su herencia y mantenerla vigente y adicionalmente contar con un ingreso que les permita salir adelante en las necesidades de su vida diaria. Una gran ventaja de esta actividad, es que los procesos productivos pueden llevarse a cabo en la casa de habitación, donde el artesano destina un área específica para elaborar los artículos artesanales que son su medio de subsistencia (Correa, 2016).

En el cuadro 2, se pueden apreciar otros rasgos que permiten identificar a la producción artesanal y que gracias a ellos ha prevalecido hasta nuestros días, aun desafiando grandes limitaciones que frenan su crecimiento y desarrollo.

Cuadro 2: Rasgos que identifican a la producción artesanal

\begin{tabular}{|l|l|}
\hline \multicolumn{1}{|c|}{ Importancia } & \multicolumn{1}{c|}{ Contribuyen al bienestar de sus comunidades. } \\
\hline Características de sus productos & Producción diversa. \\
\hline Artesanos & $\begin{array}{l}\text { Aportan conocimientos al patrimonio tangible e } \\
\text { intangible que identifica a sus comunidades. }\end{array}$ \\
\hline Defensa de tradiciones & $\begin{array}{l}\text { Ayuda a preservar sus usos y costumbres contra } \\
\text { influencias y cambios abruptos en su entorno. }\end{array}$ \\
\hline Expresión artística y cultural & $\begin{array}{l}\text { Manifiestan la belleza y particularidad de quienes } \\
\text { producen las artesanías y son refugio de la cultura } \\
\text { popular. }\end{array}$ \\
\hline Patrimonio histórico & $\begin{array}{l}\text { La producción artesanal coadyuva a preservar tra- } \\
\text { diciones, costumbres e historia de las comunidades } \\
\text { indígenas y de la identidad nacional. }\end{array}$ \\
\hline
\end{tabular}


En el cuadro número 3, se pueden visualizar algunas de las características que se presentan en los talleres de producción artesanal, y que de alguna manera pudiera decirse que explican la situación económica y social por la que atraviesan las comunidades dedicadas a esta actividad económica en nuestro país.

Cuadro 3: Características de funcionamiento de los talleres artesanales

\begin{tabular}{|l|l|}
\hline Gestión del conocimiento & $\begin{array}{l}\text { La producción artesanal se desarrolla en talleres } \\
\text { tradicionales basados en conocimiento creativo. }\end{array}$ \\
\hline Estrategias de producción & $\begin{array}{l}\text { El proceso de producción hasta nuestros días es } \\
\text { consecuencia de prácticas ancestrales. }\end{array}$ \\
\hline Estructura organizacional & $\begin{array}{l}\text { Carecen de una organización formal, pues intervie- } \\
\text { nen de manera indistinta en las labores productivas } \\
\text { todos los miembros de la familia. }\end{array}$ \\
\hline Sistema de información & $\begin{array}{l}\text { Generalmente no manejan sistemas administrativos, } \\
\text { por lo tanto, tampoco un sistema de contabilidad. }\end{array}$ \\
\hline Rentabilidad & $\begin{array}{l}\text { Al carecer de un sistema de información no hay } \\
\text { bases para medir su rentabilidad. }\end{array}$ \\
\hline $\begin{array}{l}\text { Sistemas de costos y fijación de precios } \\
\text { de venta }\end{array}$ & $\begin{array}{l}\text { Carecen de sistemas de control de sus procesos } \\
\text { productivos, por lo que sus productos son vendidos } \\
\text { a precios muy bajos, tal vez inferiores al costo. }\end{array}$ \\
\hline Tecnología & $\begin{array}{l}\text { El proceso de producción artesanal no se presta } \\
\text { para la incursión de tecnología o la implementación } \\
\text { de procesos innovadores. }\end{array}$ \\
\hline
\end{tabular}

Fuente: Elaboración propia con base en (Correa, 2016)

A manera de ejemplo, por medio del cuadro 4, se comenta a continuación, de manera muy general, el proceso de producción que desde tiempos ancestrales ha prevalecido en las comunidades de artesanos que tradicionalmente han fabricado y vendido productos de papel amate, de palma y de madera de guácimo.

Cuadro 4: Proceso de producción de artículos artesanales

\begin{tabular}{|c|c|l|}
\hline Procedencia & Materia prima & \multicolumn{1}{c|}{ Proceso de producción } \\
\hline $\begin{array}{c}\text { San Pablito, Sierra } \\
\text { Norte de Puebla }\end{array}$ & $\begin{array}{c}\text { Fibra de cor- } \\
\text { teza }\end{array}$ & $\begin{array}{l}\text { - Abastecimiento de materia prima y utensilios. } \\
\text { - Preparación de la fibra de corteza. } \\
\text { - Manufactura de papel amate. }\end{array}$ \\
\hline $\begin{array}{c}\text { Reserva de la Biosfera, } \\
\text { Tehuacán, Cuscatlán }\end{array}$ & Palma & $\begin{array}{l}\text { - Preparación de la materia prima. } \\
\text { - Manufactura de la artesanía. } \\
\text { - Aplicaciones y acabado. }\end{array}$ \\
\hline
\end{tabular}




\begin{tabular}{|c|c|c|}
\hline Procedencia & Materia prima & Proceso de producción \\
\hline Sonora & Guácimo & $\begin{array}{l}\text { - Selección de la cantidad de madera de guácimo. } \\
\text { - Corte a la medida, según el producto a elaborar. } \\
\text { - } \text { Quitar corteza, lijar y moldear con los pies, rodillas y } \\
\text { manos y dar forma al producto. } \\
\text { - Completar detalles. }\end{array}$ \\
\hline
\end{tabular}

Fuente: Elaboración propia con base en (Cruz, López, \& Neyra, 2009)

Cruz, López, y Neyra (2009) en base a sus investigaciones, agregan que prevalece en la organización de los talleres de Puebla y Sonora, objeto de su estudio, procesos productivos a cargo de la familia, las estrategias de producción obedecen a sus costumbres y tradiciones; se observa una clara división del trabajo, que se da en función del sexo y la edad y se reafirma que esta actividad es el medio de subsistencia a nivel familiar, pues sus miembros se responsabilizan desde la recolección de la materia prima hasta la terminación y venta del artículo elaborado.

En una que pudiera ser considerada como segunda etapa en la evolución del trabajo artesanal, según comentan (Hernández, Dominguez, \& Ramos, 2002) este tipo de trabajo se desarrolla a través de talleres, donde pueden detectarse dos alternativas, el centro de trabajo artesanal con obreros o bien aquel donde se depende de un solo dueño o maestro y los miembros de su familia.

Hernández et al. (2002) hablan de una tercera etapa de evolución del trabajo artesanal, dicen ellos que ésta se da cuando los talleres artesanales se convierten en talleres de manufactura artesanal.

Para ellos, un taller de manufactura artesanal, reúne las siguientes características:

- Se da una relación laboral entre el maestro y sus aprendices, en determinado momento, los aprendices, pueden convertirse en obreros expertos en cada una de las fases del proceso productivo de los artículos artesanales,

- Se presentan las circunstancias idóneas para que pueda darse una división del trabajo integral.

- En el taller se cuenta con herramientas de trabajo especializadas, que hacen el proceso productivo más eficiente y eficaz.

- Pueden implementarse medidas administrativas tendientes a elevar la productividad de todos los colaboradores, de tal suerte que se esté a la altura de la demanda del mercado al que se pertenezca. 
Uno de los objetivos que persigue este estudio es adentrarse en el medio artesanal en el que se desenvuelve la mujer ñañho, para percatarse que niveles de evolución presentan sus actividades productivas.

\section{Materiales y métodos}

Se abordó a un grupo de mujeres indígenas ñahño de la comunidad de El Rincón, Amealco de Bonfil, Querétaro, México. Con ellas se aplicaron instrumentos de recolección de datos cualitativos y cuantitativos. Como cualitativos se llevó a cabo una entrevista grupal semi estructurada, guiada por 3 profesores investigadores y 3 estudiantes tesistas del Campus Amealco, teniendo como informantes a 5 mujeres de la comunidad referida. La entrevista duró aproximadamente una hora. De manera complementaria, se realizó otra entrevista semi, estructurada a 1 artesana ñahño de la misma comunidad por parte de 2 profesores investigadores. La duración de esta entrevista también fue de aproximadamente una hora. Como cuantitativos, se realizó una encuesta a 24 mujeres de la comunidad referida, con un cuestionario compuesto por una batería de 20 preguntas (cerradas y abiertas).

\section{Resultados y discusión}

Como estructura organizativa hacia adentro del núcleo familiar, se destaca que la elaboración del tipo de artesanía se asigna por género, siendo que la elaboración de textiles la desarrolla casi por completo las mujeres, la alfarería es una actividad mixta, mientras que tallar la piedra es una actividad propiamente masculina: El tejido casi siempre lo hacen mujeres $i N o$ ? El barro ese ya le entran hombres y mujeres y el sillar es más bien para hombre.

La división del trabajo, después de asignarse conforme al género, se establece de acuerdo a una jerarquía generacional y de edades. Las competencias para hacer artesanías se trasmiten también dentro del núcleo familiar, por un proceso de aprendizaje maestro- aprendiz. Las niñas siendo aún muy pequeñas, comienzan a practicar el bordado realizando las actividades más sencillas del proceso de producción, y se les encomienda actividades más complejas conforme avanzan en edad y van desarrollando sus habilidades:

Es algo que aquí se da en la comunidad desde chiquitas. Nosotras empezamos a bordar servilletas, aunque no muy bien hechas, pero ya dese chiquitas les dan un cuadrille, hilo y aguja y les dicen: "empieza a bordar lo que tú te imagines", y ya ellas empiezan a picar un cuadrille....aunque no sea una figura... pero ya desde pequeñas están como que aprendiendo y también nosotros desde chiquitas tenemos esas ganas de aprender, así como ganarme mi dinero yo sola también, tengo que aprender a bordar para tener mi dinero y así. 
En la figura 1, se especifica cómo en el proceso de producción, se reparten las actividades de acuerdo al género y las edades. Se aclara que las mueres que no reciben ayuda por parte de otras mujeres, es porque son madres jóvenes que, o bien tienen hijos varones, o bien las hijas mujeres son lactantes o infantes, demasiado pequeñas para contribuir en la labor artesanal:

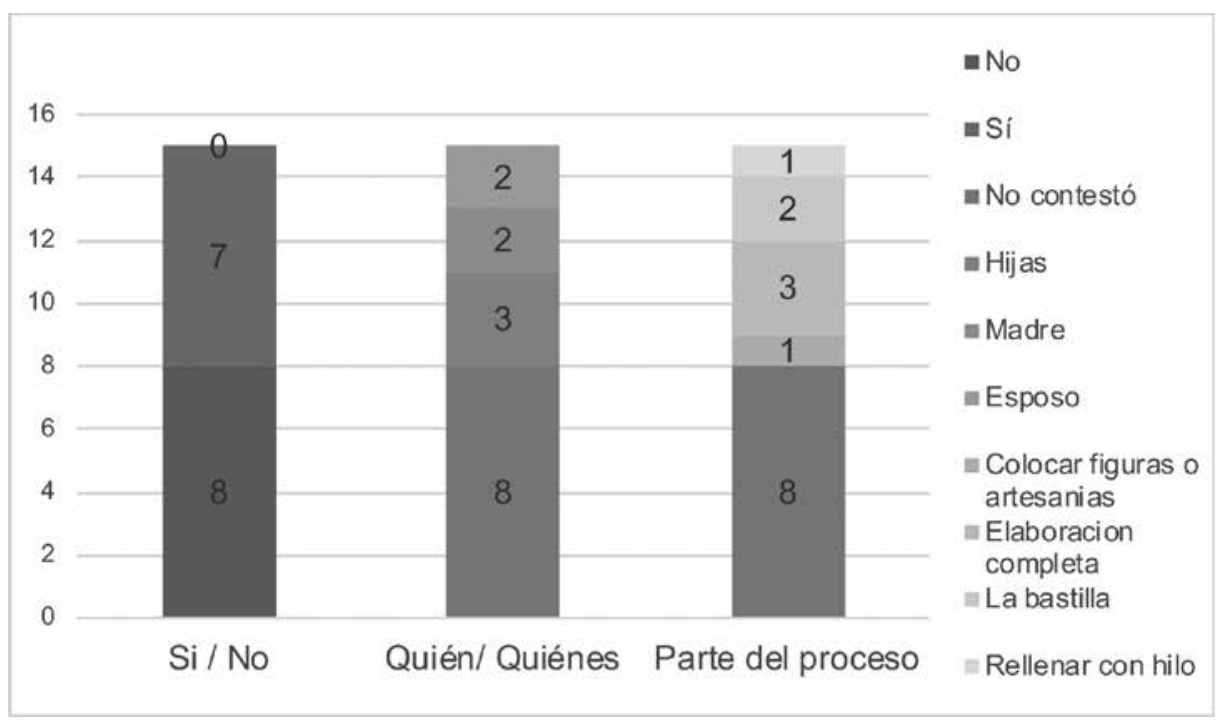

Figura 1: Ayuda para hacer artesanias.

Cabe señalar que las habilidades para elaborar las artesanías no son compartidas por todas las mujeres de la comunidad, sino que hay muchas familias que desconocen cómo desarrollar los diversos tipos de textiles (muñeca artesanal, servilletas bordadas y vestidos típicos regionales). Las artesanas identifican que las mujeres de su comunidad que desconocen el oficio del bordado, se tienen que dedicar a actividades agrícolas, calificadas como más arduas y menos femeninas:

Porque no saben. Bueno, yo no sé muy bien, pero he escuchado que la abuela de Maritza no sabe, entonces se dedica a trabajar como si fuera un hombre, porque se dedica a hacer cercas de piedra de tierra, desyerbar... Sí, porque luego yo veo en las mañanas yo la veo que sale con su pico y su pala, y pues yo creo, ósea yo digo que no sabe bordar.

En la figura 2, nos percatamos que lo horarios, e incluso las épocas del año en los cuales se hacen las artesanías, son sumamente variables. Algunas mujeres solo trabajan en verano, mientras que otras durante el transcurso de todo el año; otras tienen un horario laboral matutino, mientras que otras elijen un horario vespertino; y otras más tienen establecido elaborar textiles una vez que terminen sus quehaceres del hogar, mientras que otras simplemente lo hacen cuando disponen de tiempo y deseos de hacerlo: 


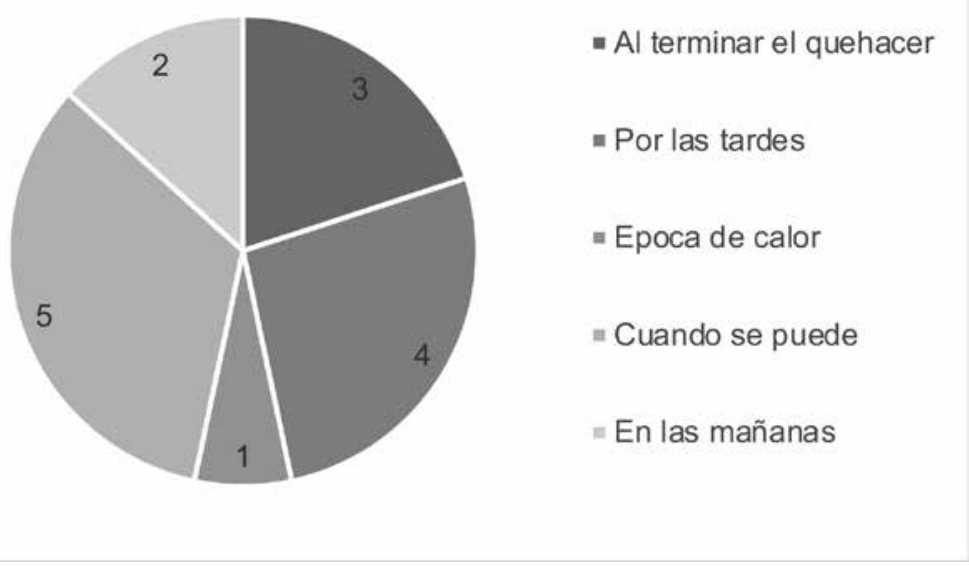

Figura 2: Momento en el que se pone hacer artesania.

En la figura 3, se muestra la dedicación diaria a la elaboración de las artesanías. La variabilidad de la jornada laboral es grande, siendo que puede ir de 1 hora a 10 horas; siendo que la media se puede situar en 4 horas por día (o media jornada laboral).

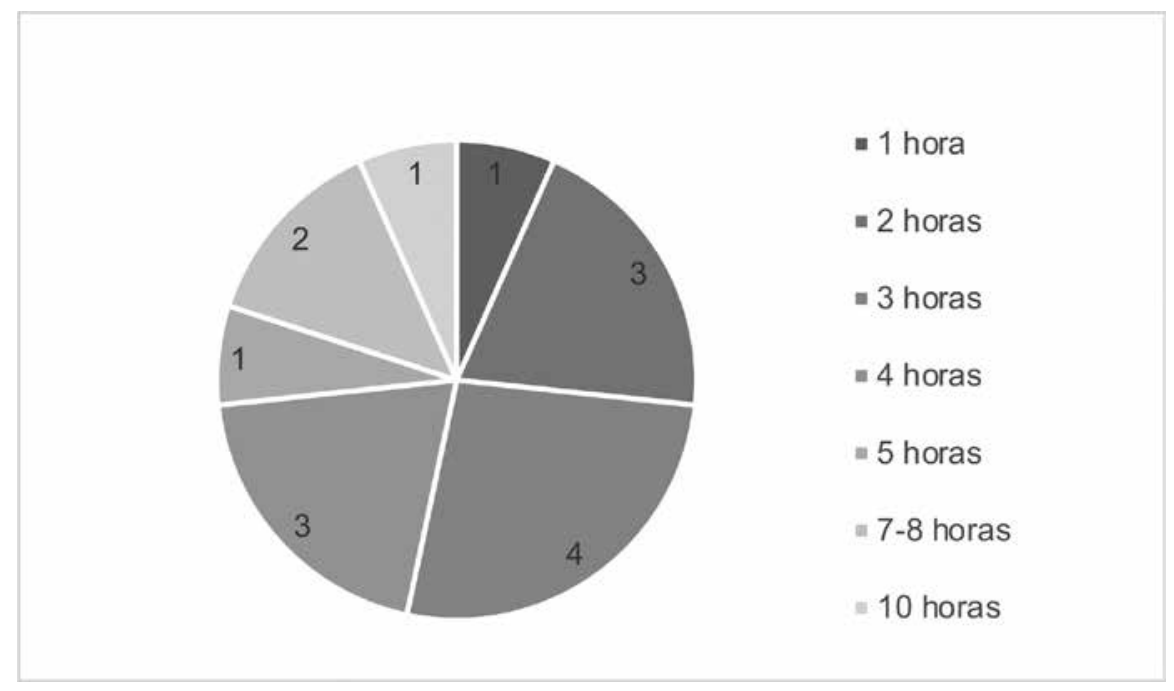

Figura 3: Horas al día dedicadas a hacer artesanías.

Como se muestra en la figura 4, la mayoría de las mujeres artesanas no se encuentra organizada para elaborar sus textiles, y de las pocas que sí lo hacen, su organización es informal, sin asignación de responsabilidades o proceso de producción fijo: 


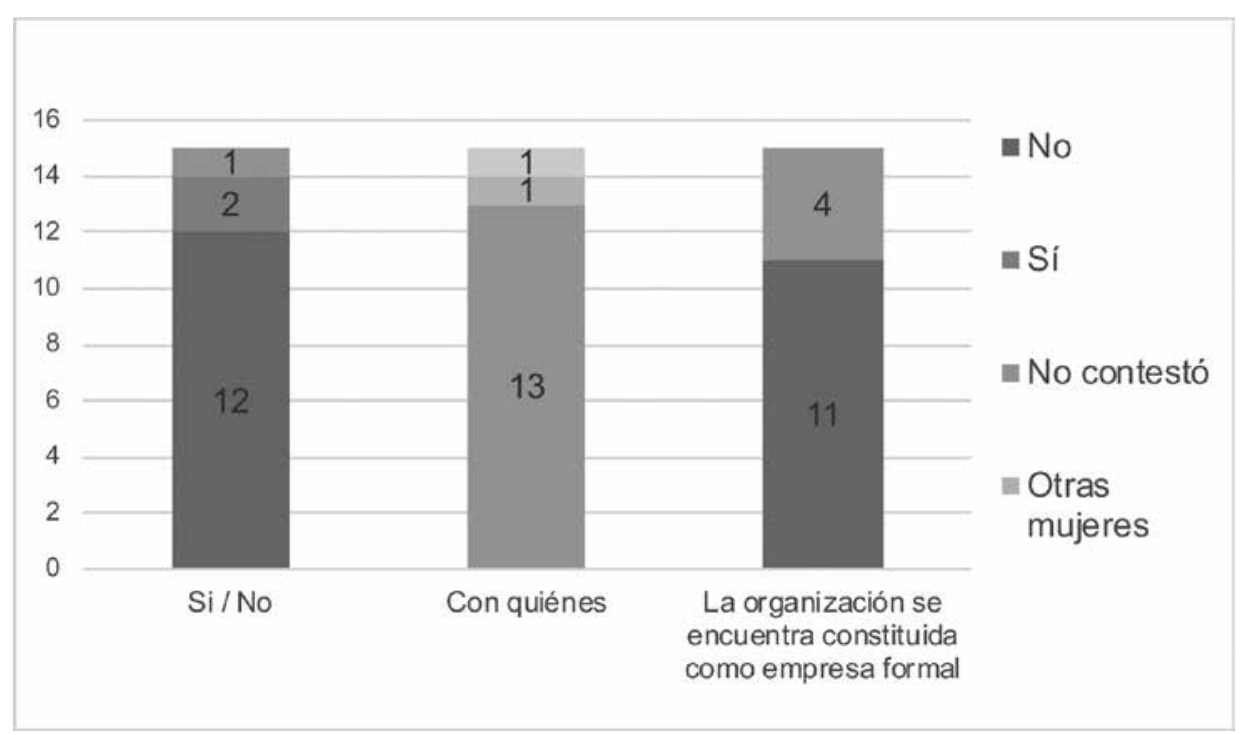

Figura 4: Organización con otras artesanas.

Se señala que, de acuerdo a los mismos informantes, el motivo por el cual la mayoría de las artesanas no se han organizado hasta ahora en una empresa formal con procesos de producción establecidos, es debido a la avaricia y el egoísmo, en donde cada mujer de la comunidad vela solo por sus propios intereses, sin interés por el bienestar colectivo:

Hay muchas señoras que son artesanas, pero cada quien por su lado. Todas quieren lo propio. No quieren estar organizadas ni nada de eso, quieren el dinero para ella solas, no para compartir con otros de la comunidad. Hasta ahorita no está la cooperativa de la comunidad, un grupo pues no.

\section{Conclusiones}

A partir del trabajo de campo, se vislumbra que la labor artesanal de las mujeres ñañho se encuentra firmemente enraizado en relaciones de género patriarcales, donde las mujeres trabajan únicamente desde su espacio doméstico, en actividades que son ampliación de los quehaceres del hogar, como es la confección de textiles.

A su vez, el trabajo infantil femenino sin remuneración se vuelve una estrategia de sobrevivencia del núcleo familiar, siendo las condiciones económicas tan precarias bajo estos medios de producción, que no se pueden dar el lujo de reconocer en ello explotación laboral. Se pone a consideración que incluir a las niñas en la producción artesanal en unidades familiares, es una de las principales causas de su deserción escolar y, por ende, de limitarles el acceso a la esfera pública. 
Por otro lado, se enfatiza que, dado al declarado aislamiento de las mujeres ñañho dentro de sus límites simbólicos hogareños, una interacción con otras mujeres para crear una organización de índole productiva, resulta difícil de suponer que se pueda dar de forma espontánea e inmediata.

Se aclara con respecto a lo afirmado anteriormente, que la conformación de unidades de producción artesanales de mujeres indígenas queretanas de ninguna manera se contempla como una imposibilidad, ya que, en el mismo grupo étnico en otras comunidades aledañas, sí que se cuenta con la presencia de micro, pequeñas y medianas empresas que han prosperado (incluso al grado de colocar sus productos en el mercado extranjero) compuestas de las mismas actrices sociales.

Sin embargo, lo que se manifiesta es que, para incubar una empresa artesanal en este grupo de mujeres indígenas en particular, se vuelve prioritario establecer diversos cursos de capacitación previos (de integración comunitaria y emprendimiento empresarial) que las dote de las herramientas culturales y administrativas mínimas para sobrevivir y prosperar y en un entorno tan competitivo como el de la venta de artesanías en México.

\section{Lista de referencias}

Correa, L. A. (2016). El sector artesanal en México y el combate contra la pobreza. Transitare 2 (2), $233-250$.

Cruz, M., M., López, B., C., \& neyra, G. , L. (2009). Procesos de producción artesanal. (Fonart, Ed.) Artesanías y medio ambiente, 145.

Del Carpio, O., P. S. (2012). Entre el textil y el ámbar: las funciones psicosociales del trabajo artesanal en artesanos tsotsiles de la ilusión, Chiapas, México. Athenea Digital, 12(2), 185 - 198.

Hernández, G, J., Dominguez, H., M., \& Ramos, S., A. O. (Septiembre / diciembre de 2002). Canales de distribución y competitividad en artesanías. Espiral, IX(25).

Novelo, V. (Septiembre / Diciembre de 2002). Ser indio, artista y artesano en México. Espiral, IX(25), 165 - 177. 